\title{
Patient expectations and their satisfaction in the context of public hospitals
}

\author{
This article was published in the following Dove Press journal: \\ Patient Preference and Adherence \\ 22 September 2016 \\ Number of times this article has been viewed
}

\author{
Adugnaw Berhane' \\ Fikre Enquselassie ${ }^{2}$ \\ 'College of Health Sciences, Debre \\ Berhan University, Debre Berhan, \\ Ethiopia; ${ }^{2}$ School of Public Health, \\ Addis Ababa University, Addis \\ Ababa, Ethiopia
}

Correspondence: Adugnaw Berhane School of Public Health, Addis Ababa University, PO Box 100796, Addis Ababa, Ethiopia

$\mathrm{Tel}+2519113$ 91। I

Email adugnawmph@yahoo.com
Background: Patient expectations have been recognized as a factor for patient satisfaction in medical consultations. Although various studies explored the relationship between patient expectations and patient satisfaction in developed countries, there is a lack of research evidence in Ethiopia where the meeting of patient expectations could relate to satisfaction.

Objective: To assess the relationship between patients' expectations and their satisfaction in the consultation of patients at the outpatient department.

Study design: Data were collected regarding preconsultation expectations and postconsultation experiences of adult patients attending nine public hospitals. A systematic random sampling method was used where every fifth patient attending an outpatient department was selected. The patients were interviewed before consultation and after consultation to assess whether their pre-consultation expectations were met and to assess how satisfied they were with the consultation. Cronbach's alpha statistic was used to assess the reliability of the expectation questionnaires, and paired $t$-test was used to assess any differences between previsit expectations and postvisit experiences. Logistic regression techniques were used to assess variables considered as independent factors for patient satisfaction.

Results: A total of 776 patients were interviewed, giving a response rate of $92.3 \%$. About $93.7 \%$ mentioned a diagnosis for their condition as a reason for their current hospital visits. There is a significant difference between preconsultation expectation and postconsultation expectation. Postconsultation expectation, perceived health status, and perceived control on health were factors identified as increasing patient satisfaction. In addition, the presence of any disappointments or worries, previous experience in health care, and extent of influence on the consultation had a negative influence on satisfaction.

Conclusion: Postconsultation expectation impacts patient satisfaction. Health care service providers should emphasize the actual experience of consultation.

Keywords: patient expectation, patient satisfaction, hospital health care, Ethiopia

\section{Introduction}

Patients have a specific agenda when visiting the health service providers, which usually reflects concerns and problems they want the health service providers to address during consultation; it might also include their desires for specific services. ${ }^{1}$ Many studies were concerned with measuring patients' expectations in diverse viewpoints going from the general expectations about health care accessibility and facilities to the more particular expectations related to health care providers' interpersonal and clinical skills. Interestingly, most of the patients' expectations are mainly focused on the health care provider's ability to show interest, ie, listening to patients' concerns, which is reported to be the general nature of expectation. ${ }^{2}$ Other studies suggested that the most common expectations were health care providers' 
understanding, showing interest, and discussing problems or doubts. ${ }^{2,3}$

In addition, expectations are related to receiving information on pain management and advice on how to return to normal life, ${ }^{4}$ or information about prognosis and prevention. ${ }^{5}$ Generally, particular expectations for prescriptions, tests, or referrals appear to be far fewer than those for diagnosis, information, listening, or understanding. ${ }^{2}$ Although it might appear that technical aspects (eg, prescriptions or tests) are of high importance for patients, it is reported that needs for support or information are more valued than technical interventions. ${ }^{2,6}$

Some studies used the concept of met expectations as a valid measure of satisfaction with the provided service, suggesting a direct relationship between unmet expectations and dissatisfaction, and vice versa. ${ }^{6-9}$ However, other studies showed controversial results regarding this relationship, ${ }^{10-12}$ while others related fulfilled expectations to a more important consultation outcome than satisfaction, for instance, seeking further medical care and adherence. ${ }^{2,13}$

It seems that some form of relationship exists between perceived service quality, patient expectations, and satisfaction. ${ }^{14}$ However, the high satisfaction ratings reported cannot be considered to point to the fact that patients had a good experience in relation to particular services, for example, experiences do not necessarily correlate with the user's evaluations of the services. ${ }^{15}$ Thus, valuing the quality of the service in terms of met expectations and higher patient satisfaction is tricky, as a previous review of the literature revealed that only $20 \%$ of studies considered expectations as determinants of satisfaction. ${ }^{16}$ In that review, ${ }^{16}$ patient's satisfaction is shaped by prior satisfaction with the health care, health status, age, and personal predisposition, which make it a very subjective evaluation of the service that would considerably vary according to the individual. Studies have defined patient satisfaction as an expression of the gap between the expected and perceived characteristics of a service, ${ }^{17,18}$ whereas patient expectation is defined as the aspects of the hospital characteristics anticipated by prospective patients, regardless of preference, or what could be considered ideal. ${ }^{19}$

A previous study demonstrated that patient-reported experiences and fulfillment of expectations were the most important predictors of overall patient satisfaction. ${ }^{18}$ Meeting patients' expectations is one measure of the quality of health care systems. ${ }^{20}$ The evidence base in this area has been growing, but there is still a relative scarcity of studies, leading to some difficulties. ${ }^{2,21}$ For example, there are a number of expectations, different ways of communicating them, and a discrepancy in the literature concerning methods to ascertain, draw, and monitor patient expectations. ${ }^{2}$

Little is understood from the patient's perspective of health care experiences, especially in the developing country context. Thus, this study was intended to assess the relationship between patients' expectations and their satisfaction with the consultation provided by health care providers in the outpatient department of public hospitals in Ethiopia. It also aims to describe patients' perceptions of health care and their health conditions.

\section{Methods}

\section{Study design and patients}

A cross-sectional study that used interviewer-administered questionnaires was carried out to assess patient expectation and its relation to patient satisfaction on outpatient services. Adult patients who received care from outpatient clinics (general, medical, and surgical) were the subjects of the study.

\section{Sampling and data collection method}

\section{Sample size determination}

A single population proportion sample size determination formula was used with the following assumptions: Proportion of patients satisfied with hospital care services was taken to be $53 \%$, according to a study done in Amhara Region, ${ }^{22}$ margin of error of 0.05 , nonresponse rate of $10 \%$, the desired confidence level of $95 \%$, and design effect of 2 . Thus, the required sample size calculated was 841 .

\section{Sampling procedure}

Proportional allocation of sample was done to each hospital and department by considering the average patient flow of the outpatient departments in the same month of the preceding year and the month prior to the actual data collection period. The sample is regarded as a multistage systematic random sample because we had used a sampling frame of selecting hospitals as estimating average daily patient flow, which was estimated using the patient registration book in the outpatient departments. We used a systematic sampling technique to select respondents among outpatients every day from Monday to Friday of the week. For the purpose of this study, every fifth patient attending an outpatient department was selected.

\section{Data collection procedure}

The study was approved by the Institutional Review Board of College of Health Sciences, Addis Ababa University, Ethiopia. Written permission from the Amhara Regional 
Health Bureau and respective study hospital administrators was also sought. Verbal informed consent was obtained from all participants prior to the interview. The information was gathered on two occasions. Right after being selected, the aims of the study were explained to the patient, their participation was requested assuring them the confidentiality of the information they would be providing, and the first questionnaire was administered and the preconsultation data were filled; then, the second questionnaire was administered after they completed their consultation and treatment (ie, at their exit). Because of low literacy among the study population, the research assistants did the interviewing using a structured interview guide. The data were collected in the local language - Amharic.

\section{Questionnaire}

A structured questionnaire was adapted from a previous study that intended to assess realistic patient expectations in the processes of health care, ${ }^{17}$ and questions were prepared by the investigator. To customize and adapt the tool to the local situation, we initially pretested it among 50 patients in the hospital. On the basis of the findings, minor modifications were made to the questionnaire.

\section{Preconsultation questionnaires}

Information was gathered concerning the patient's realistic expectations about a specific consultation. The questionnaire included questions from the perspective of the patient's expectations in these terms: "Regarding today's consultation with your health care provider, to what extent do you agree with the following in relation to your visit?" They had to answer 20 items scored on a five-point scale: "strongly agree $=1$, agree $=2$, neither agree nor disagree $=3$, disagree $=4$, and strongly disagree $=5$ " (Figure S1). The 20 items were comprised into four categories: Four items were related to finding their way around, 5 items were categorized under health care providerpatient communication style, five items were categorized under treatment/procedures performed and 6 items explored health care provider approach to information. Data were also obtained on health care experiences in the past 12 months.

\section{Attitudes and characteristics}

In this section of the questionnaire, questions related to preferences about making decisions about medical care using Degner scale, ${ }^{23}$ extent of feeling to influence the consultation, extent of agreement to take a positive attitude toward oneself, extent of control over health, perceived health status, and presence of any long-standing illness, disability, or infirmity were included.
Data on sociodemographic characteristics (age, sex, marital status, educational status, occupation, residence, and payment status) were also collected.

\section{Postconsultation questionnaire}

As soon as the patient left the health care provider's room after completing their treatment, an exit questionnaire was administered to assess the extent to which patients' expectations of their visit and consultation were met. This questionnaire contained 20 items to assess patients' extent of agreement in relation to their visit and consultation, which had been scored on a five-point scale: "strongly agree $=1$, agree $=2$, neither agree nor disagree $=3$, disagree $=4$, and strongly disagree $=5$ " (Figure S2). The highest expectation could be represented by a value of 1 . Hence, higher expectations are reflected by lower scores.

\section{The visit overall}

Questions that show extent of influence in the consultation, things that needed to be done at this consultation but were not done, or things that disappointed, worth of the consultation, and overall satisfaction with their visit were included. In this study, overall patient satisfaction was measured with a single Likert-type item question asking respondents to rate their overall satisfaction with their consultation, on a five-point Likert rating item ranging from "very satisfied" to "very dissatisfied." The single Likert-type global patient satisfaction measurement has been validated and used in other studies. ${ }^{17,18,24,25}$

\section{Statistical analysis}

The pre- and postconsultation expectation Likert data were analyzed using the interval measurement scale. ${ }^{26}$ Overall pre- and postconsultation expectation mean scores were calculated by summing scores for each of the individual domains. Paired-samples $t$-test was used to compare the mean difference between pre- and postconsultation expectation scores. Satisfaction was dichotomized into satisfied and dissatisfied. The very satisfied and satisfied were categorized under the satisfied group, and neither satisfied nor dissatisfied, dissatisfied, and very dissatisfied were categorized as dissatisfied group. Multivariable logistic regression was performed with predictive variables with patient satisfaction. Variables were selected if their bivariate significance showed $P \leq 0.1$ to enable the likelihood of variables attaining statistical significance when the confounding effect of another variable was controlled. $P$-values of $<0.05$ were considered significant. 
We used SPSS version 17.0 (SPSS, Inc., Chicago, IL, USA) for data analyses. Internal reliability for each scale was evaluated by Cronbach's alpha. Cronbach's alpha for the preconsultation expectation scale was 0.86 , and Cronbach's alpha for postconsultation scale 0.94, which suggest that the scales showed good to excellent internal consistency. ${ }^{27}$

\section{Results}

\section{Sociodemographic characteristics of respondents}

Of the target number of 841 patients, 776 participated in the study, giving a response rate of $92.3 \%$. A higher proportion of the respondents were males (468 [60\%]). The median age of the respondents was 31 years, with a range of $18-80$ years. Approximately $21 \%$ of patients reported themselves as illiterate, and two-thirds were rural inhabitants. A higher proportion of respondents were farmers, $474(61 \%)$ and paying patients, 753 (97\%) (Table 1).

\section{Health care visits by respondents}

Table 2 shows that 172 (22.2\%) respondents had previous experience in the medical health care services. In addition,

Table I Sociodemographic characteristics of respondents $(N=776)$

\begin{tabular}{|c|c|c|}
\hline Characteristics & Frequency & Percent \\
\hline \multicolumn{3}{|l|}{ Age, years } \\
\hline Median age & 31 & \\
\hline \multicolumn{3}{|l|}{ Sex } \\
\hline Female & 308 & 39.7 \\
\hline Male & 468 & 60.3 \\
\hline \multicolumn{3}{|l|}{ Marital status } \\
\hline Married or cohabiting with partner & 543 & 70.0 \\
\hline Divorced or separated & 54 & 7.0 \\
\hline Widowed & 19 & 2.4 \\
\hline Single & 160 & 20.6 \\
\hline \multicolumn{3}{|l|}{ Educational status } \\
\hline Illiterate & 162 & 20.9 \\
\hline Read and write & 152 & 19.6 \\
\hline Grade I-8 & 196 & 25.3 \\
\hline Grade 9-10 & 114 & 14.7 \\
\hline Grade $11-12$ & 4.3 & 5.5 \\
\hline Higher education & 109 & 14.0 \\
\hline \multicolumn{3}{|l|}{ Occupation } \\
\hline Employed & 101 & 13.0 \\
\hline Merchant & 125 & 16.1 \\
\hline Farmer & 474 & 61.1 \\
\hline No job & 43 & 5.5 \\
\hline Other & 33 & 4.3 \\
\hline \multicolumn{3}{|l|}{ Residence } \\
\hline Urban & 255 & 32.9 \\
\hline Rural & 521 & 67.1 \\
\hline \multicolumn{3}{|l|}{ Payment status } \\
\hline Paying & 753 & 97.0 \\
\hline Free & 23 & 3.0 \\
\hline
\end{tabular}

Table 2 Health care visits and reasons for the current visit $(\mathrm{N}=776)$

\begin{tabular}{|c|c|c|}
\hline Characteristics & Frequency & Percent \\
\hline \multicolumn{3}{|c|}{ Previous experience of health service utilization } \\
\hline Yes & 172 & 22.2 \\
\hline No & 604 & 77.8 \\
\hline \multicolumn{3}{|c|}{ Reasons for the current health service visit* } \\
\hline To get diagnosis & 727 & 93.7 \\
\hline For reassurance & 57 & 7.3 \\
\hline To get the results of test & 41 & 5.3 \\
\hline Treatment & 384 & 49.3 \\
\hline For a health checkup/appointment & 43 & 5.5 \\
\hline To ask for a referral & 36 & 4.6 \\
\hline \multicolumn{3}{|c|}{ Duration of symptom/problem for the current visit } \\
\hline One week or less & 240 & 30.9 \\
\hline Between I week and I month & 359 & 46.3 \\
\hline I-6 months & 91 & 11.7 \\
\hline $6-12$ months & 42 & 5.4 \\
\hline$\geq 12$ months & 44 & 5.7 \\
\hline
\end{tabular}

Note: *Multiple response question.

$240(30.9 \%)$ of the respondents mentioned their symptoms (health problem) lasted 1 week or less. Three hundred and fifty nine $(46.3 \%)$ patients reported symptom duration between 1 week and 1 month. Of the total 776 participants, 93.7\% visited hospitals for the diagnosis of their health conditions, while $49.3 \%$ mentioned prescription refill and/or in need of medical or surgical procedure as reasons for their current consultation.

\section{Respondents' perception toward decision-making in health care and their health conditions}

As shown in Table 3, only one-fifth of the respondents preferred to take an active role in treatment-related decisions; eleven (1.4\%) and $145(18.7 \%)$ of participants preferred to make final decisions about medical care and final selection of the treatment after considering health care provider's opinion, respectively.

About $488(62.9 \%)$ respondents perceived that they could moderately influence the consultation to achieve the outcome they wanted. About a quarter of respondents strongly agree to take a positive attitude toward themselves, whereas fewer (18\%) perceived that they had a lot of control over their health. Regarding self-perceived health status, approximately two-thirds of patients perceived that their health status ranged from good to very good, relative to their age. About $87 \%$ of patients perceived that they did not have long-standing illness, disability, or infirmity. In those respondents with chronic illness, hypertension, diabetes, heart problem, back pain, and headache were mentioned as the most common long-standing health problems. 
Table 3 Respondents' perception toward decision making in health care and their health conditions

\begin{tabular}{|c|c|c|}
\hline Perceptions & $\begin{array}{l}\text { Number } \\
(\mathbf{N}=776)\end{array}$ & Percent \\
\hline \multicolumn{3}{|l|}{ Preference in making decisions about medical care } \\
\hline $\begin{array}{l}\text { I prefer to make the final decision about } \\
\text { which treatment I will receive }\end{array}$ & 11 & 1.4 \\
\hline $\begin{array}{l}\text { I prefer to make the final selection of } \\
\text { my treatment after seriously considering } \\
\text { my doctor's opinion }\end{array}$ & 145 & 18.7 \\
\hline $\begin{array}{l}\text { I prefer that my doctor and I share } \\
\text { responsibility for deciding which treatment } \\
\text { is best for me }\end{array}$ & 412 & 53.1 \\
\hline $\begin{array}{l}\text { I prefer that my doctor makes the final } \\
\text { decision about which treatment will be used, } \\
\text { but seriously considers my opinion }\end{array}$ & 138 & 17.8 \\
\hline $\begin{array}{l}\text { I prefer to leave all decisions regarding my } \\
\text { treatment to my doctor }\end{array}$ & 70 & 9.0 \\
\hline \multicolumn{3}{|c|}{ Influence the consultation to achieve the outcome you want } \\
\hline A lot & 152 & 19.6 \\
\hline A moderate amount & 488 & 62.9 \\
\hline A little & 113 & 14.6 \\
\hline Not at all & 23 & 3.0 \\
\hline \multicolumn{3}{|c|}{ Extent of agreement to take a positive attitude toward him/herself } \\
\hline Strongly agree & 200 & 25.8 \\
\hline Agree & 464 & 59.8 \\
\hline Neither agree nor disagree & 26 & 3.4 \\
\hline Disagree & 86 & II.I \\
\hline Strongly disagree & 0 & 0 \\
\hline \multicolumn{3}{|l|}{ Extent of control over your health } \\
\hline A lot of control & $14 \mid$ & 18.2 \\
\hline Some control & 427 & 55.0 \\
\hline A little control & 92 & 11.9 \\
\hline No control & 116 & 14.9 \\
\hline \multicolumn{3}{|l|}{ Perceived health status } \\
\hline Excellent & 0 & 0 \\
\hline Very good & 227 & 29.3 \\
\hline Good & 283 & 36.5 \\
\hline Fair & 164 & 21.1 \\
\hline Poor & 76 & 9.8 \\
\hline Very poor & 26 & 3.4 \\
\hline \multicolumn{3}{|l|}{ Presence of longstanding illness, disability or infirmity } \\
\hline Yes & 104 & 13.4 \\
\hline No & 672 & 86.6 \\
\hline
\end{tabular}

\section{Respondents' perception of the overall health care visit}

About two-thirds of the respondents were able or attempted to influence the consultation to get the outcome they wanted. About 211 (27.2\%) respondents said that they were disappointed with the consultation. Some of the things that needed to be done at this consultation that were not done were: patients perceived that the health care provider did not know their real health problem, the provider did not give enough time for discussion, the provider did not reassure them about their health condition, the provider did not use diagnostic equipment and/or laboratory investigations, the provider did not conduct physical examination, and the provider gave short consultation time. About 116 (14.9\%) of respondents believed that the consultation was not worthwhile. When we evaluated respondents' global satisfaction level, 243 (31.3\%) and 351 (45.2\%) were very satisfied and satisfied, respectively (Table 4 ).

\section{Differences in preconsultation expectation and postconsultation experience}

Paired sample $t$-test was performed to assess the mean differences between the patient's expectations before consultation and his/her experiences after consultation. The results revealed a significant difference in overall expectation from preconsultation to postconsultation $(\bar{x} 1=39.62 \pm 10.27)$ to $(\bar{x} 2=47.34 \pm 14.45)$ with $(t=-12.95, P<0.001)$. This mean expectation score increase from preconsultation to postconsultation indicated that patients expectations in the preconsultation were not met. Among the subscales, all subscales except the health care provider-patient communication style subscale had significant difference between preconsultation and postconsultation expectations (Table 5).

\section{Predictors of patient's satisfaction}

Table 6 lists independent predictors of patient satisfaction. The logistic model fit well (Hosmer-Lemeshow test, $P>0.05$ ) and was statistically significant, $\chi^{2}=86.72, P<0.0001$. The model explained $14.9 \%$ (Nagelkerke $R^{2}$ ) of the variance in patient satisfaction and correctly classified $71.6 \%$ of cases.

The multivariable logistic regression showed that the probability of patient satisfaction is contingent on postconsultation expectation score level. The higher the score

Table 4 Postvisit perceptions and patient's satisfaction of consultation in the outpatient department

\begin{tabular}{lll}
\hline Postvisit perceptions & $\begin{array}{l}\text { Number } \\
(\mathbf{N}=\mathbf{7 7 6})\end{array}$ & Percent \\
\hline Extent of influence on the consultation & & \\
A lot & 72 & 9.3 \\
A moderate amount & 510 & 65.7 \\
A little & 126 & 16.2 \\
Not at all & 68 & 8.8 \\
Are there things that disappointed you in the current consultation? \\
No & 565 & 72.8 \\
Yes & 211 & 27.2 \\
Perceived worthiness of the consultation & & \\
Worth it & 267 & 34.4 \\
Too early to say & 393 & 50.6 \\
Not worth it & 116 & 14.9 \\
Overall, how satisfied are you with your visit this time & \\
Very satisfied & 243 & 31.3 \\
Satisfied & 351 & 45.2 \\
Neither satisfied nor dissatisfied & 123 & 15.9 \\
Dissatisfied & 41 & 5.3 \\
Very dissatisfied & 18 & 2.3 \\
\hline
\end{tabular}


Table 5 Mean differences between pre- and postconsultation expectation

\begin{tabular}{|c|c|c|c|c|}
\hline Expectations & $\begin{array}{l}\text { Preconsultation } \\
\text { Mean } \pm \text { SD }\end{array}$ & $\begin{array}{l}\text { Postconsultation } \\
\text { Mean } \pm \text { SD }\end{array}$ & $\mathbf{t}$ & $P$-value \\
\hline Receiving instructions from health care provider & $7.9 \pm 2.51$ & $8.80 \pm 3.06$ & -6.36 & $<0.001$ \\
\hline Health care provider-patient communication style & $11.24 \pm 3.55$ & $10.92 \pm 3.78$ & I.7I & 0.087 \\
\hline Treatment given/procedures performed & $9.20 \pm 2.53$ & $11.77 \pm 3.09$ & -18.23 & $<0.001$ \\
\hline Health care provider approach to information & $11.24 \pm 3.57$ & $15.85 \pm 6.67$ & -17.66 & $<0.001$ \\
\hline Overall expectation & $39.62 \pm 10.27$ & $47.34 \pm 14.45$ & -12.95 & $<0.001$ \\
\hline
\end{tabular}

Note: Low mean values = high expectations and vice versa.

Abbreviation: SD, standard deviation.

of postconsultation expectation, less likely the patients are satisfied. Participants with excellent to good self-perceived health status were 3.5 times (OR, 3.53, 95\% CI; 2.27-5.49) more likely satisfied than fair to very poor self-perceived health status. Similarly, the odds of satisfaction were higher among participants who had a lot of perceived control on health compared to their counterparts. The odds of satisfaction were significantly lower among patients who were disappointed (OR, 0.32, 95\% CI; 0.22-0.47) compared to patients who were not disappointed. Similarly, the odds of satisfaction were lower among participants who had previous health care service experience compared to their counterparts. On the other hand, compared to patients who felt a lot of influence on the consultation, the odds of satisfaction for those with no influence was significantly lower (OR, 0.58 , 95\% CI; 0.37-0.91).

\section{Discussion}

To the best of our knowledge, this is the first pre- and postconsultation study aimed to assess the relationship between patients' expectations and their satisfaction in the consultation of patients at the outpatient department across nine public hospitals in Ethiopia.

The reasons for hospital visits mentioned by the majority of the participants were either to get a diagnosis for their health condition or for prescription refill, medical, or surgical procedure.

When we compared the summed mean values of pre- and postconsultation, there was an increment in mean values during postconsultation. This was also shown in all expectation subcategories. This indicates that patients had high expectations before consultation but faced difficulty in the actual medical setting in fulfilling these expectations. The results of this study pointed out that there were differences between preconsultation expectation and postconsultation expectation/experience. Among the subscales, receiving instruction, treatment given/procedures performed, and health care provider approach to information showed significant difference, but health care provider-patient communication style did not show significant difference.

Multivariable regression analysis illustrated that postconsultation expectation, perceived control on health, perceived health status, perceived extent of influence on the consultation, any disappointments, and health care experience were determinants of patient satisfaction.

Our result indicates that preconsultation expectation was not a predictor for patient satisfaction. Patient satisfaction was determined by the postconsultation expectations, but these expectations were not fulfilled. This result is inconsistent with prior studies, which underlined the importance

Table 6 Results of the logistic regression analysis showing independent association of global patient satisfaction

\begin{tabular}{|c|c|c|c|c|c|}
\hline \multirow[t]{2}{*}{ Variables } & \multirow[t]{2}{*}{$\beta$} & \multirow[t]{2}{*}{$P$-value } & \multirow{2}{*}{$\begin{array}{l}\text { Odds } \\
\text { ratio }\end{array}$} & \multicolumn{2}{|c|}{ 95\% Cl for $\operatorname{Exp}(\mathrm{B})$} \\
\hline & & & & Lower & Upper \\
\hline Post-consultation expectations mean score & -0.012 & 0.038 & 0.988 & 0.976 & 0.999 \\
\hline Pre-consultation expectations mean score & -0.011 & 0.188 & 0.990 & 0.974 & 1.005 \\
\hline Perceived control over health (does not $=0, A$ lot of control $=I$ ) & 0.749 & $<0.001$ & 2.115 & 1.343 & 3.329 \\
\hline Perceived health status (fair to very poor $=0$, excellent to good $=I$ ) & 1.263 & $<0.001$ & 3.538 & 2.277 & 5.496 \\
\hline Felt extent of influence to the consultation (moderate to not at all $=0$, a lot $=\mathrm{I}$ ) & -0.538 & 0.019 & 0.584 & 0.372 & 0.917 \\
\hline Disappointed $($ no $=0$, yes $=1$ ) & -1.121 & 0.000 & 0.326 & 0.223 & 0.476 \\
\hline Experience $(\mathrm{no}=0$, yes $=\mathrm{l})$ & -0.531 & 0.021 & 0.588 & 0.374 & 0.924 \\
\hline Constant & 0.908 & 0.106 & 2.480 & & \\
\hline
\end{tabular}

Notes: $\mathrm{N}=776$. Nagelkerke's $R^{2}=0.149 . \chi^{2}=86.72, P<0.000$ I. Negative $\beta$-values for the Pre-consultation expectation and for the Post-consultation expectation indicate higher odds to be included in the satisfied group. For other variables with positive $\beta$-values, there is a higher odds to be included in the satisfied group. Abbreviation: $\mathrm{Cl}$, confidence interval. 
of fulfilled expectation for patient satisfaction. ${ }^{28,29}$ This relationship between postconsultation expectations and high patient satisfaction is supported by other studies..$^{6-9,17,30}$

Among the sociodemographic variables, age was significantly associated with patient's satisfaction in the bivariate analysis but insignificant in the final model. Previous experience in medical care had negative association with patient satisfaction. This might be due to a previous exposure to a hospital with less or no satisfactory service, which might in turn raise a concern on patient's safety and clinical effectiveness.

We found that patients were more satisfied when they had a lot of perceived control over their own health. This is in line with a prior study which showed that the personal ability to control one's environment has a positive effect on satisfaction. ${ }^{31}$ This is also supported by a research finding that has shown a positive satisfaction with perceived control over the childbirth environment, even though the setting was in the maternity care. ${ }^{32}$

Interestingly, patients concerned with the consultation or disappointed with the consultation were unsatisfied. This could be explained by several reasons. Since patients expect the hospital as a place that diagnoses their problems and helps them get well, their expectations have not been met. This is also expressed by emotional feelings where disappointment with the current health care service depicts the patients' satisfaction. They might have also described the condition of their current illness - either they have debilitating and incurable disease and/or not sure about their future health.

Patients who perceived their health status was relatively good were more satisfied. This is supported by a study done in Ethiopia in which perceived health status was seen as a determinant of patient satisfaction. ${ }^{33}$ This is also supported by other studies, reporting that a low perceived health status is associated with lower patient satisfaction. ${ }^{18,34,35}$ Besides, Grøndahl VA et al, ${ }^{36}$ explained in their study that patients could never acknowledge their satisfaction when they assume that their health condition is deteriorating and when they lack the hope to be cured. Patients who have a lot extent of influence on the consultation negatively predicted patient's satisfaction. This finding needs further investigations.

The findings of this study must be interpreted with the attention to the following limitations. This study mainly focused on the processes of hospital health care and did not include the structural aspects and outcome of health care. The result is only from the patients' point of view about the consultation; it did not assess the providers' perspective of medical consultation. The study only includes patients in the outpatient department of general, medical, and surgical specialties. Hence, we cannot generalize this result to the inpatient departments and other outpatient departments of respective hospitals. The study included patients from public hospitals only, and so, it is difficult to generalize the findings to the private hospital context. However, the findings of this study could be generalized to hospitals having similar settings. The dependent variable is measured using only a single Likert item; thus, it only measures global level of patient satisfaction. Even though a global measure of patient satisfaction is valid in other studies, it may not be sensitive for some parts of the measurement.

On the basis of our findings, we recommend that health service providers and managers focus on patient experience to enhance patient satisfaction. We recommend that studies incorporate health service providers to assess the complete picture of patient satisfaction and the match in expectation between patients and health service providers. Future research is also needed to explore the reasons that patients felt the extent of influence on consultations had a negative association with satisfaction.

\section{Conclusion}

There was a significant difference between preconsultation expectations and post consultation expectations. Postconsultation expectation had a positive association with patient satisfaction. Factors such as perceived health status and perceived control on health were the ones that positively influenced patient satisfaction, and any presence of disappointments, felt extent of influence to the consultation, and previous experience in health care service were factors that negatively influenced patient satisfaction.

\section{Acknowledgments}

The authors thank all individuals who participated in this study. They also thank Addis Ababa University for financing this study.

\section{Author contributions}

All authors contributed toward data analysis, drafting and critically revising the paper and agree to be accountable for all aspects of the work.

\section{Disclosure}

The authors report no conflicts of interest in this work.

\section{References}

1. Rao JK, Weinberger M, Kroenke K. Visit-specific expectations and patient-centered outcomes: a literature review. Arch Fam Med. 2000; 9(10):1148-1155. 
2. Ruiz-Moral R, Perula de Torres LA, Jaramillo-Martin I. The effect of patients' met expectations on consultation outcomes. A study with family medicine residents. J Gen Intern Med. 2007;22(1):86-91.

3. Kravitz RL, Cope DW, Bhrany V, Leake B. Internal medicine patients' expectations for care during office visits. J Gen Intern Med. 1994;9(2): 75-81.

4. Turner JA, LeResche L, Korff MV, Ehrlich K. Back pain in primary care: patient characteristics, content of initial visit, and short-term outcomes. Spine. 1998;23(4):463-469.

5. Sanchez-Menegay C, Stalder H. Do physicians take into account patients' expectations? J Gen Intern Med. 1994;9(7):404- 406.

6. Williams S, Weinman J, Dale J, Newman S. Patient expectations: what do primary care patients want from the GP and how far does meeting expectations affect patient satisfaction? J Fam Pract. 1995;12(2): 193-201.

7. Marple RL, Kroenke K, Lucey CR, Wilder J, Lucas C. Concerns and expectations in patients presenting with physical complaints. Frequency, physician perceptions and actions, and 2-week outcome. Arch Intern Med. 1997;157(13):1482-1488.

8. Jackson JL, Kroenke K. The effect of unmet expectations among adults presenting with physical symptoms. Ann Intern Med. 2001;134(9): 889-897.

9. Zebiene E, Razgauskas E, Basys V, et al. Meeting patient's expectations in primary care consultations in Lithuania. Int $J$ Qual Health Care. 2004;16(1):83-89.

10. Froehlich GW, Welch H. Meeting walk-in patients' expectations for testing. Effects on satisfaction. J Gen Intern Med. 1996;11(8): 470-474.

11. Peck BM, Ubel PA, Roter DL, et al. Do unmet expectations for specific tests, referrals, and new medications reduce patients' satisfaction? J Gen Intern Med. 2004;19(11):1080-1087.

12. Padmashree $S$, Isaacs A. Expectations of primary care patients in rural Karnataka. Pak J Med Sci. 2007;23(4):534-537.

13. Licina P, Johnston M, Ewing L, Mark P. Patient expectations, outcomes and satisfaction: related, relevant or redundant? Evid Based Spine Care J. 2012;3(4):13-19.

14. Conway T, Willcocks S. The role of expectations in the perception of health care quality: developing a conceptual model. Int J Health Care Qual Assur. 1997;10(2):131-140.

15. Williams B, Coyle J, Healy D. The meaning of patient satisfaction: An explanation of high reported levels. Soc Sci Med. 1998;47(9): 1351-1359

16. Crow R, Gage H, Hampson S, et al. The measurement of satisfaction with healthcare: implications for practice from a systematic review of the literature. Health Technol Assess. 2002;6(32):1-244.

17. Bowling A, Rowe G, McKee M. Patients' experiences of their healthcare in relation to their expectations and satisfaction: a population survey. $J$ R Soc Med. 2013;106(4):143-149.

18. Schoenfelder T, Klewer J, Kugler J. Determinants of patient satisfaction: a study among 39 hospitals in an in-patient setting in Germany. Int J Qual Health Care. 2011;23(5):503-509.

19. O’Malley K, Roddey T, Gartsman G, Cook K. Outcome expectancies, functional outcomes and expectancy fulfilment for patients with shoulder problems. Med Care. 2004;42:139-146.
20. Kravitz RL, Callahan EJ, Paterniti D, Antonius D, Dunham M, Lewis C. Prevalence and sources of patients' unmet expectations for care. Ann Intern Med. 1996;125(9):730-737.

21. Kravitz R. Measuring patients' expectations and requests. Ann Intern Med. 2001;134(9):881-888.

22. Mitike G, Mekonnen A, Osman M. Satisfaction on outpatient services in hospitals of the Amhara region. Ethiop Med J. 2002;40:387-395.

23. Degner LF, Sloan JA, Venkatesh P. The control preferences scale. Can J Nurs Res. 1997;29(3):21-43.

24. Robertson O, Dunbar M. Patient satisfaction compared with general health and disease-specific questionnaires in knee arthroplasty patients. $J$ Arthroplasty. 2001;16:476-482.

25. Hossain M, Parfitt DJ, Beard DJ, et al. Does pre-operative psychological distress affect patient satisfaction after primary total hip arthroplasty? BMC Musculoskel Disord. 2011;12:122.

26. Boone HN Jr, Boone DA. Analyzing Likert data. J Extension. 2012; 50(2):Number 2TOT2.

27. Gliem JA, Gliem RR. Calculating, interpreting, and reporting Cronbach's alpha reliability coefficient for Likert-type scales. Midwest Research to Practice Conference in Adult, Continuing, and Community Education; October 8-10; 2003; Columbus, OH: The Ohio State University.

28. Mahomed N, Liang M, Cook E, et al. The importance of patient expectations in predicting functional outcomes after total joint arthroplasty. J Rheumatol. 2002;29(6):1273-1279.

29. Noble P, Conditt MA, Cook KF, Mathis KB. The John Insall Award: patient expectations affect satisfaction with total knee arthroplasty. Clin Orthop Relat Res. 2006;452:35-43.

30. Hageman MG, Briet JP, Bossen JK, Blok RD, Ring DC, Ana-Maria V. Do previsit expectations correlate with satisfaction of new patients presenting for evaluation with an orthopaedic surgical practice? Clin Orthop Relat Res. 2015;473:716-721.

31. Veenhoven R. Developments in satisfaction-research. Soc Indic Res. 1996;37:1-46.

32. Natalie RS. Perceived Control and Maternal Satisfaction with the Childbirth Experience [doctoral thesis]. Lawrence: Psychology, University of Kansas; 2011.

33. Tateke T, Woldie M, Ololo S. Determinants of patient satisfaction with outpatient health services at public and private hospitals in Addis Ababa, Ethiopia. Afr J Prim Health Care Fam Med. 2012;4(1):384.

34. Zhang Y, Rohrer J, Borders T, Farrell T. Patient satisfaction, self-rated health status, and health confidence: an assessment of the utility of single-item questions. Am J Med Qual. 2007;22:42-49.

35. Shou-Hisa C, Ming-Chin Y, Tung-uang C. Patient satisfaction with and recommendation of a hospital: effects of interpersonal and technical aspects of hospital care. Int J Qual Health Care. 2003;15(4): 345-355.

36. Grøndahl VA, Wilde-Larsson B, Karlsson I, Hall-Lord ML. Patients' experiences of care quality and satisfaction during hospital stay: a qualitative study. Eur J Pers Cent Healthc. 2012;1(1):185-192. 


\section{Supplementary materials \\ Preconsultation questionnaire on patients' expectations of health care}

Thank you for taking part in our study of patients' expectations for health care. All the information you provide is completely confidential. Please answer the following questions before your consultation. Thank you for your help.

These questions are about your expectations of your health care. To what extent do you agree with the following in relation to your visit and consultation?

\section{Postconsultation questionnaire on patients' expectations of health care}

Thank you for taking part in the second part of our study of patients' expectations for health care. All the information you provide is completely confidential.

Please answer the following questions after your consultation. Thank you again for your help.

We would like to ask you about the extent to which your expectations of the visit and consultation were met.

To what extent do you agree with the following in relation to your visit and consultation?

\begin{tabular}{|c|c|c|c|c|c|c|}
\hline $\begin{array}{l}\text { Serial } \\
\text { no }\end{array}$ & & $\begin{array}{l}\text { Strongly } \\
\text { agree } \\
\text { (1) }\end{array}$ & $\begin{array}{l}\text { Agree } \\
(2)\end{array}$ & $\begin{array}{l}\text { Neither agree } \\
\text { nor disagree } \\
\text { (3) }\end{array}$ & $\begin{array}{l}\text { Disagree } \\
\text { (4) }\end{array}$ & $\begin{array}{l}\text { Strongly } \\
\text { disagree } \\
\text { (5) }\end{array}$ \\
\hline I & Receiving instructions from health care provider & & & & & \\
\hline 1 & Be given clear information about where to go & $\square$ & $\square$ & $\square$ & $\square$ & $\square$ \\
\hline 2 & Be given an appointment for a convenient date/time & $\square$ & $\square$ & $\square$ & $\square$ & $\square$ \\
\hline 3 & Be seen on time & $\square$ & $\square$ & $\square$ & $\square$ & $\square$ \\
\hline 4 & The reception staff will be helpful & $\square$ & $\square$ & $\square$ & $\square$ & $\square$ \\
\hline II & $\begin{array}{l}\text { Health care provider-patient communication style } \\
\text { The health care provider I see will be: }\end{array}$ & $\square$ & $\square$ & $\square$ & $\square$ & $\square$ \\
\hline 5 & Helpful & & & & & \\
\hline 6 & Respectful and treats me with dignity & $\square$ & $\square$ & $\square$ & $\square$ & $\square$ \\
\hline 7 & Knowledgeable about/understand my health condition/problem & $\square$ & $\square$ & $\square$ & $\square$ & $\square$ \\
\hline 8 & Be clear and easy to understand & $\square$ & $\square$ & $\square$ & $\square$ & $\square$ \\
\hline 9 & Involve me in decisions about my treatment & $\square$ & $\square$ & $\square$ & $\square$ & $\square$ \\
\hline III & $\begin{array}{l}\text { Treatment given/procedures performed } \\
\text { I will be given: }\end{array}$ & & & & & \\
\hline 10 & A physical examination & $\square$ & $\square$ & $\square$ & $\square$ & $\square$ \\
\hline 11 & Tests/investigations & $\square$ & $\square$ & $\square$ & $\square$ & $\square$ \\
\hline 12 & A diagnosis or to have a previous diagnosis confirmed & $\square$ & $\square$ & $\square$ & $\square$ & $\square$ \\
\hline 13 & A new, changed, or repeat prescription & $\square$ & $\square$ & $\square$ & $\square$ & $\square$ \\
\hline 14 & A referral to another doctor/specialist/ & $\square$ & $\square$ & $\square$ & $\square$ & $\square$ \\
\hline IV & $\begin{array}{l}\text { Health care provider approach to information } \\
\text { Information will be given: }\end{array}$ & & & & & \\
\hline 15 & Reassurance about my condition & $\square$ & $\square$ & $\square$ & $\square$ & $\square$ \\
\hline 16 & $\begin{array}{l}\text { Advice about my health/condition } \\
\text { I will be given a full explanation, in clear language about: }\end{array}$ & $\square$ & $\square$ & $\square$ & $\square$ & $\square$ \\
\hline 17 & What caused my condition/problem & $\square$ & $\square$ & $\square$ & $\square$ & $\square$ \\
\hline 18 & How to manage the condition/symptoms/pain & $\square$ & $\square$ & $\square$ & $\square$ & $\square$ \\
\hline 19 & $\begin{array}{l}\text { The benefits/side effects or complications/risks of treatment } \\
\text { I will be given the opportunity to: }\end{array}$ & $\square$ & $\square$ & $\square$ & $\square$ & $\square$ \\
\hline 20 & Discuss the problems in my life & $\square$ & $\square$ & $\square$ & $\square$ & $\square$ \\
\hline
\end{tabular}

Figure SI Preconsultation questionnaire on patients' expectations of health care. 


\begin{tabular}{|c|c|c|c|c|c|c|}
\hline $\begin{array}{l}\text { Serial } \\
\text { no }\end{array}$ & & $\begin{array}{l}\text { Strongly } \\
\text { agree } \\
\text { (1) }\end{array}$ & $\begin{array}{l}\text { Agree } \\
(2)\end{array}$ & $\begin{array}{l}\text { Neither nor } \\
\text { disagree } \\
\text { (3) }\end{array}$ & $\begin{array}{l}\text { Disagree } \\
\text { (4) }\end{array}$ & $\begin{array}{l}\text { Strongly } \\
\text { disagree } \\
\text { (5) }\end{array}$ \\
\hline I & Receiving instructions from health care provider & & & & & \\
\hline 1 & I was given clear information about where to go & $\square$ & $\square$ & $\square$ & $\square$ & $\square$ \\
\hline 2 & I was given an appointment for a convenient date/time & $\square$ & $\square$ & $\square$ & $\square$ & $\square$ \\
\hline 3 & I was seen on time & $\square$ & $\square$ & $\square$ & $\square$ & $\square$ \\
\hline 4 & I found that the reception/liaison staff were helpful & $\square$ & $\square$ & $\square$ & $\square$ & $\square$ \\
\hline II & $\begin{array}{l}\text { Health care provider-patient communication style } \\
\text { The health care provider I saw: }\end{array}$ & $\square$ & $\square$ & $\square$ & $\square$ & $\square$ \\
\hline 5 & Was helpful & $\square$ & $\square$ & $\square$ & $\square$ & $\square$ \\
\hline 6 & Was respectful and treated me with dignity & $\square$ & $\square$ & $\square$ & $\square$ & $\square$ \\
\hline 7 & Was knowledgeable about/understood my health condition/problem & $\square$ & $\square$ & $\square$ & $\square$ & $\square$ \\
\hline 8 & Was clear and easy to understand & $\square$ & $\square$ & $\square$ & $\square$ & $\square$ \\
\hline 9 & Involved me in decisions about my treatment & $\square$ & $\square$ & $\square$ & $\square$ & $\square$ \\
\hline III & $\begin{array}{l}\text { Treatment given/procedures performed } \\
\text { I was given: }\end{array}$ & & & & & \\
\hline 10 & A physical examination & $\square$ & $\square$ & $\square$ & $\square$ & $\square$ \\
\hline 11 & Tests/investigations & $\square$ & $\square$ & $\square$ & $\square$ & $\square$ \\
\hline 12 & A diagnosis or had a previous diagnosis confirmed & $\square$ & $\square$ & $\square$ & $\square$ & $\square$ \\
\hline 13 & A new, changed, or repeat prescription & $\square$ & $\square$ & $\square$ & $\square$ & $\square$ \\
\hline 14 & A referral to another doctor/specialist & $\square$ & $\square$ & $\square$ & $\square$ & $\square$ \\
\hline IV & $\begin{array}{l}\text { Health care provider approach to information } \\
\text { I was given: }\end{array}$ & & & & & \\
\hline 15 & Reassurance about my condition & $\square$ & $\square$ & $\square$ & $\square$ & $\square$ \\
\hline 16 & $\begin{array}{l}\text { Advice about my health/condition } \\
\text { I was given a full explanation, in clear language about: }\end{array}$ & $\square$ & $\square$ & $\square$ & $\square$ & $\square$ \\
\hline 17 & What caused my condition/problem & $\square$ & $\square$ & $\square$ & $\square$ & $\square$ \\
\hline 18 & How to manage the condition/symptoms/pain & $\square$ & $\square$ & $\square$ & $\square$ & $\square$ \\
\hline 19 & The benefits/side effects or complications/risks of treatment & $\square$ & $\square$ & $\square$ & $\square$ & $\square$ \\
\hline 20 & I was given the opportunity to discuss problems in my life & $\square$ & $\square$ & $\square$ & $\square$ & $\square$ \\
\hline
\end{tabular}

Figure S2 Postconsultation questionnaire on patients' expectations of health care.

\section{Publish your work in this journal}

Patient Preference and Adherence is an international, peer-reviewed, open access journal that focuses on the growing importance of patient preference and adherence throughout the therapeutic continuum. Patient satisfaction, acceptability, quality of life, compliance, persistence and their role in developing new therapeutic modalities and compounds to optimize clinical outcomes for existing disease states are major areas of interest for the journal. This journal has been accepted for indexing on PubMed Central. The manuscript management system is completely online and includes a very quick and fair peer-review system, which is all easy to use. Visit http://www. dovepress.com/testimonials.php to read real quotes from published authors. 